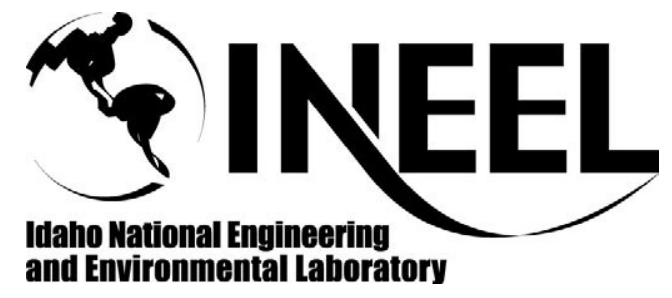

\author{
INEEL/CON-04-02464 \\ PREPRINT
}

The Interaction Of A Circular Synthetic Jet With A Cross-Flow Boundary Layer

\author{
Jennifer M. Shuster \\ Robert J. Pink \\ Donald M. McEligot \\ Douglas R. Smith
}

June 6-9, 2005

$35^{\text {th }}$ AIAA Fluid Dynamics Conference \& Exhibit

This is a preprint of a paper intended for publication in a journal or proceedings. Since changes may be made before publication, this preprint should not be cited or reproduced without permission of the author.

This document was prepared as an account of work sponsored by an agency of the United States Government. Neither the United States Government nor any agency thereof, or any of their employees, makes any warranty, expressed or implied, or assumes any legal liability or responsibility for any third party's use, or the results of such use, of any information, apparatus, product or process disclosed in this report, or represents that its use by such third party would not infringe privately owned rights. The views expressed in this paper are not necessarily those of the U.S. Government or the sponsoring agency. 
35th AIAA Fluid Dynamics Conference and Exhibit, 6-9 June 2005, Toronto, Canada

\title{
The Interaction of a Circular Synthetic Jet with a Cross-flow Boundary Layer
}

\author{
Jennifer M. Shuster* \\ University of Wyoming, Laramie, Wyoming, 82071, USA \\ Robert J. Pink ${ }^{\dagger}$ and Donald M. McEligot ${ }^{\ddagger}$ \\ Idaho National Laboratory (INL), Idaho Falls, Idaho, 83415, USA \\ Douglas R. Smith ${ }^{\S}$ \\ University of Wyoming, Laramie, Wyoming, 82071, USA
}

\begin{abstract}
The interaction of a circular synthetic jet with a laminar cross-flow boundary layer was investigated experimentally in the Matched-Index-of-Refraction flow facility at Idaho National Laboratory. Two orifice orientations were investigated, straight and inclined. For each orifice, phase-averaged and time-averaged PIV measurements were made at $L_{\circ} / D_{\circ}=1.0$ and 2.0 with $\operatorname{Re}_{U}=250$ and $r=1.12$. Refractive index matching between the working fluid and the model material permitted experimental measurements of the flow field inside the actuator orifice and cavity simultaneously. At $L_{\circ} / D_{\circ}=1.0$, the vortex ring formed at the orifice during the expulsion portion of the actuator cycle blocks the boundary layer causing the flow to divert over and around the ring. This vortex ring does not escape the near-vicinity of the orifice and is subsequently re-ingested. At the same stroke, inclining the orifice axis $30^{\circ}$ downstream leads to a jet comprised of a train of vortex rings that penetrates the cross-flow. At $\mathrm{L}_{\circ} / \mathrm{D}_{\circ}=\mathbf{2 . 0}$, both the straight and inclined orifices create large discrete vortex rings that penetrate deep into the cross-flow, and consequently do not affect the boundary layer much beyond the near-field of the orifice.
\end{abstract}

\section{Introduction}

$\mathrm{T}$ o better understand how synthetic jets can be used for aerodynamic flow control, it is necessary to understand the interaction between a synthetic jet and a cross-flow boundary layer. Insight into this interaction has only recently become available, see for example, Smith, ${ }^{1,2}$ Milanovic and Zaman, ${ }^{3,4}$ Schaeffler. ${ }^{5}$ Of these studies perhaps the most insightful measurements were obtained by Schaeffler ${ }^{5}$ who used PIV to obtain detailed flow field measurements near the actuator orifice in a synthetic jet cross-flow interaction. These measurements show the complex flow field that ensues when a circular synthetic jet interacts with a cross-flow boundary layer. Prior measurements ${ }^{1,4}$ suggest that the interaction of a synthetic jet with a

\footnotetext{
*Engineering/Scientist I, CFD Development \& Geometry, The Boeing Company, P.O. Box 3707, Seattle, WA, 98124, AIAA Student Member.

${ }^{\dagger}$ INL, Idaho Falls, ID 83415

¥Technical Leader, INL, Idaho Falls, ID 83415. Also Professor Emeritus, University of Arizona

$\S$ Associate Professor, Department of Mechanical Engineering, Dept 3295, 1000 E University Ave, University of Wyoming, Laramie, WY 82071, AIAA Senior Member.

Copyright (C) 2005 by Douglas R. Smith. Published by the American Institute of Aeronautics and Astronautics, Inc. with permission.
} 
cross-flow boundary layer bears a strong resemblance to a steady jet in a cross-flow. That is, velocity profiles of the boundary layer downstream of the actuator suggest a structure that is consistent with the existence of a weak counter-rotating vortex pair in the downstream boundary layer. How such a structure evolves from the interaction of the synthetic jet and the cross flow has not yet been examined. Moreover, any analogy between a synthetic jet and a steady jet is likely to be poor near the orifice, as the near-field of a synthetic jet is characterized by the periodic formation of discrete vortices. In addition, the geometric characteristics of the actuator, e.g. the shape of the orifice, the inside contour shape of the orifice, or the orientation of the orifice axis relative to the cross flow direction, are likely to affect the interaction of a synthetic jet flow with a cross-flow boundary layer.

The focus of the current work is to examine in detail the interaction of a circular synthetic jet with a laminar cross-flow including the near- and far-fields of the interaction, the flow inside the orifice and the flow near the orifice inside the actuator cavity. To obtain these flow-field details, the experiments presented here took advantage of refractive-index-matching between the working fluid and the material of the actuator to gain undistorted optical access to both the orifice and cavity flow-fields of the synthetic jet actuator.

\section{Experimental Setup}

All experiments were performed in the Matched-Index-of-Refraction flow facility at Idaho National Laboratory (INL). This facility is a closed-circuit flow loop using mineral oil as the working fluid. A photograph of the flow facility is shown in figure 1 (flow is from left to right). The test section of the facility is approximately $2.43 \mathrm{~m}$ in length with a cross-section of $0.61 \mathrm{~m} \times 0.61 \mathrm{~m}$. The test section walls are 1.5 in. thick polycarbonate with windows of 0.75 in. thick soda-lime float glass. For all tests presented here, the freestream velocity of the oil was $12.2 \mathrm{~cm} / \mathrm{s}$.

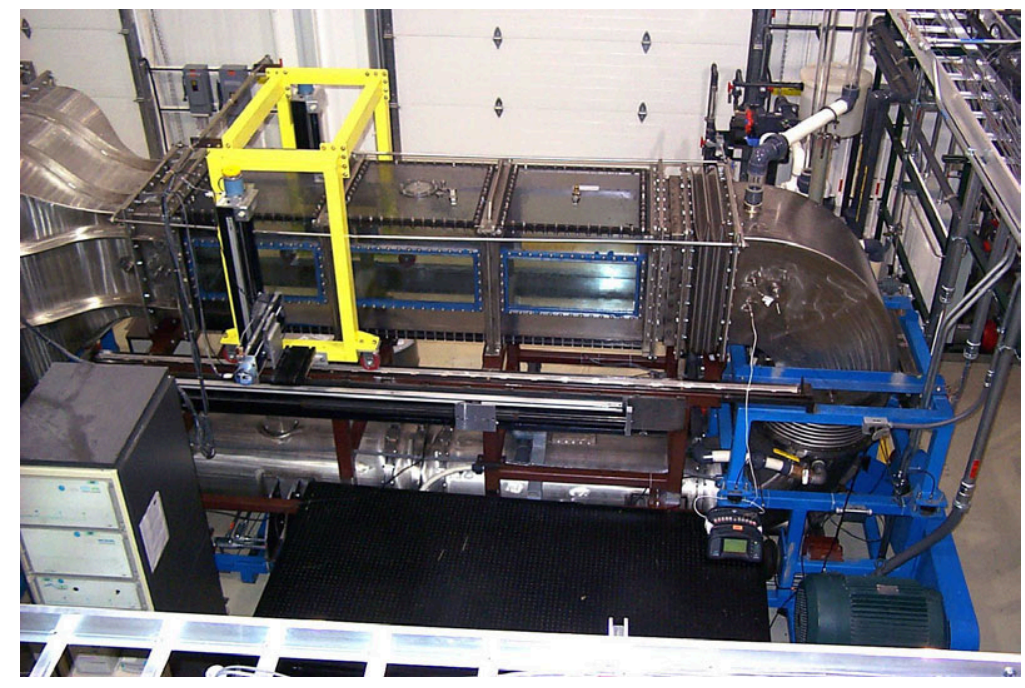

Figure 1. Test section of the Matched-Index-of-Refraction flow facility at INL.

A model constructed of aluminum and polished quartz was suspended in the test section. The model consisted of four $1.27 \mathrm{~cm}$ thick plates which span nearly the entire width of the test section. The first, second and fourth plates were all constructed of aluminum. The leading edge of a NACA 0009 wing section was used as the contour for the leading edge of the first plate. The third plate was fabricated from fire-polished quartz. A $2.54 \mathrm{~cm}$ polished hole was located in the center of this plate. In the current experiments, two hole orientations were investigated: one with the hole axis aligned normal to the plate $\left(\alpha=90^{\circ}\right)$, and a second with the hole axis inclined downstream at an angle of $\alpha=30^{\circ}$. A quartz cylinder with an inner diameter of 
$10.2 \mathrm{~cm}$ and a wall thickness of $0.64 \mathrm{~cm}$ was centered about the hole and was bonded to the plate with epoxy (figure 2). A piston, connected through a shaft to a linear slide, was placed inside the quartz cylinder. This piston-cylinder combination formed the synthetic jet actuator. The piston trajectory was controlled with a stepper motor connected to the drive shaft of the linear slide. Use of micro-stepping in the stepper motor controller provided smooth, continuous piston trajectories.

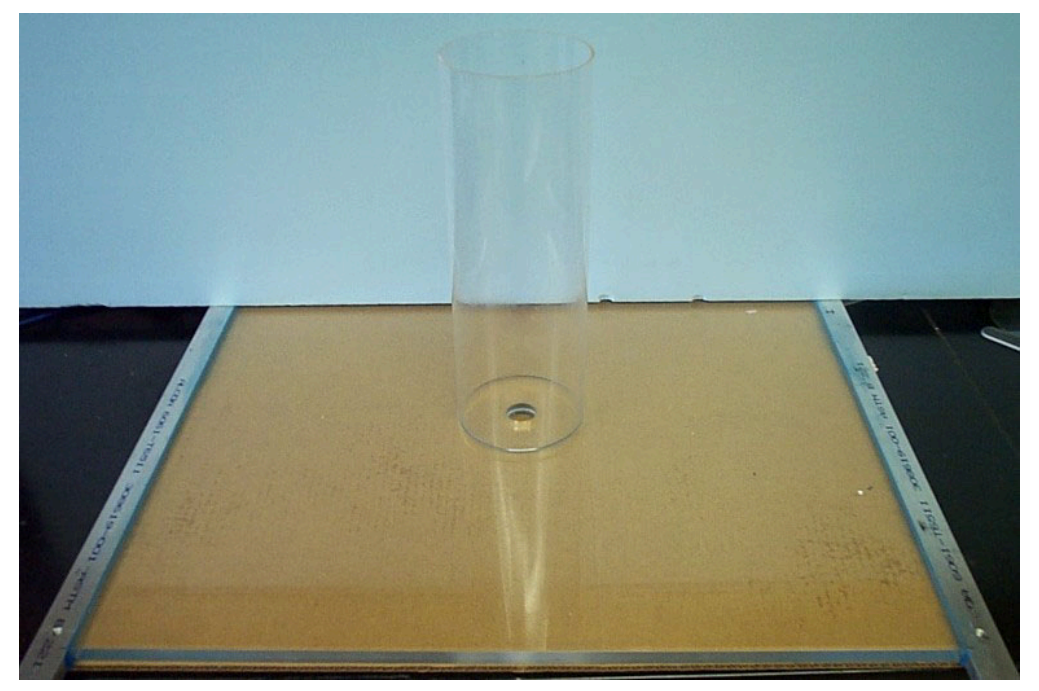

Figure 2. Synthetic jet model consisting of the quartz plate with orifice and quartz cylinder.

The unique and distinctive feature of the INL facility and the above experimental setup is that the mineral oil and the quartz have very similar indices of refraction. To obtain equal indices of refraction for the working fluid and model material, the oil temperature was adjusted. In the current experiments, the temperature of the mineral oil was maintained at approximately $23.3^{\circ} \mathrm{C}$, matching the refractive index of the quartz at the wavelength of the Nd:YAG laser light $(532 \mathrm{~nm})$.

Two-dimensional velocity vector fields lying in the center plane of the jet were obtained with PIV. Measurements were obtained for two fields of view, labeled near and far. Sketches of these fields of view are shown in figure 3. The measurements were obtained with a LaVision PIV system. This system used a 12-bit, 4 Mpixel camera, and velocity vector fields were obtained using the double exposure/double frame crosscorrelation mode. The fluid was seeded with polyamid $20 \mu \mathrm{m}$ particles and illuminated by a $120 \mathrm{~mJ} / \mathrm{pulse}$ Nd:YAG laser.

The velocity vector fields were calculated from image pairs using a multi-pass approach, two passes with an interrogation window of $64 \times 64$ pixels and two subsequent passes with an interrogation window of $32 \times$ 32 pixels. For each set of passes the window overlap was 50\%. The images were then post-processed using a median filter scheme to identify and reject potentially erroneous vectors. The data were then exported to MATLAB for further analysis of the flow field characteristics.

Phase-averaged velocity vector fields were obtained at equally-spaced phase angles of $18^{\circ}$ from $0^{\circ}$ to $162^{\circ}$ and from $198^{\circ}$ to $342^{\circ}$. Because of limitations in the experimental setup, images were not obtained at $180^{\circ}$; and additional vector fields were obtained at $170^{\circ}$ and $190^{\circ}$. A phase angle of $0^{\circ}$ corresponds to the starting location of the piston. At this location the piston displacement and the piston velocity are zero. A phase angle of $180^{\circ}$ corresponds to the location of the peak displacement of the piston and the end of the fluid ejection phase of the cycle. At each phase angle, 64 image pairs were taken and averaged for a mean vector field. In addition, a mean vector field composed of 1024 image pairs was obtained at each non-dimensional stroke and Reynolds number combination.

The scaling parameters for the synthetic jet is based on the slug flow model for vortex ring formation. 


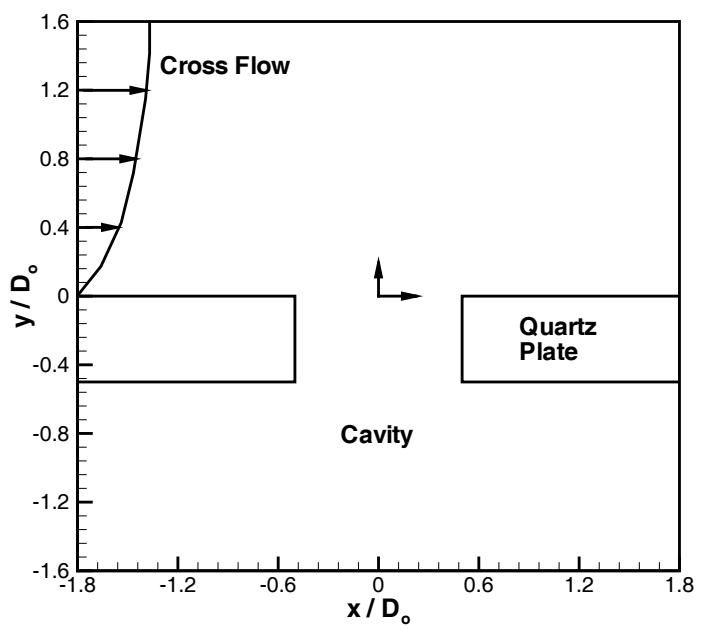

(a) Near-field

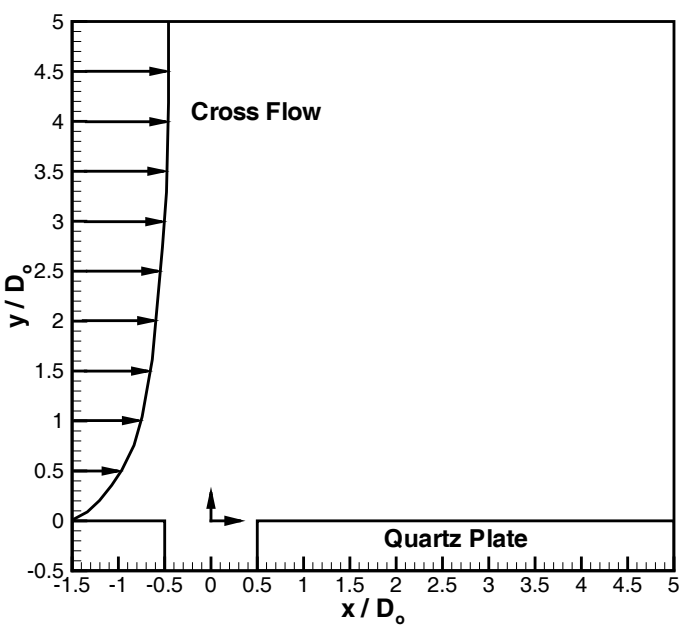

(b) Far-field

Figure 3. Flow fields of view for the near-field and far-field measurements.

By analogy then, the formation parameters of interest are the non-dimensional fluid stroke length, defined as the ratio of fluid stroke length to orifice diameter, $\mathrm{L}_{\circ} / \mathrm{D}_{\circ}$, and a Reynolds number based on the average jet velocity derived from $L_{\circ}, R_{U_{\circ}} \cdot R_{U}$ is defined as, $U_{\circ} D_{\circ} / \nu$ where $U_{\circ}$ is the mean velocity of a cylindrical slug of fluid and is obtained by averaging over time $T_{0}$, the piston transit time during the ejection phase of the actuator cycle. ${ }^{6}$

\section{Experimental Results}

The interaction between the synthetic jet and the cross-flow boundary layer was studied for two synthetic jet orifice orientations, straight and $30^{\circ}$ inclined. For both orientations, PIV measurements were obtained for $\mathrm{L}_{\circ} / \mathrm{D}_{\circ}=1.0$ and 2.0 at $\mathrm{Re}_{U_{\circ}}=250$. The momentum ratio for the synthetic jet and the cross-flow was $r \equiv U_{\circ}^{2} / U_{\infty}^{2}=1.12$. At each of the actuator operating conditions, phase-averaged and time-averaged measurements were obtained.

\section{A. Synthetic Jet from a Straight Orifice in a Cross-Flow: Phase-averaged Flow}

Contours of the spanwise vorticity, $\omega_{z}$, with an overlay of velocity vectors (normalized by the freestream velocity) are presented in figure 4 at six phase angles for the straight orifice and $\mathrm{L}_{\circ} / \mathrm{D}_{\circ}=1.0$. Figures $4(\mathrm{a})$ - (c) show the flow during the expulsion portion $\left(\phi<180^{\circ}\right)$ of the actuator cycle. In this sequence, we see the formation of the vortex ring at the orifice. The ring is tilted upstream with a thicker core on the downstream side. During the ring formation, the boundary layer separates just upstream of the orifice, flowing up and over the forming vortex ring. The formation of the ring appears to block the boundary layer flow at the orifice, creating a large region of low momentum fluid downstream of the orifice that persists through much of the actuator cycle. In the cross-flow, the boundary layer is laminar, and it appears from the concentrations of positive vorticity in the separated flow that the Kelvin-Helmholtz instability is present 
in the shear layer. As the suction portion of the actuator cycle begins (figure $4 \mathrm{~d}$ - $\mathrm{f}$ ), fluid from the upstream boundary layer, which is being drawn into the orifice, and the separated shear layer envelope the formation vortex ring diminishing the concentration of vorticity on the upstream portion of the ring. Ultimately, this portion of the ring is re-ingested while the downstream section of the ring remains approximately motionless and appears to weaken. During the suction portion of the cycle, fluid appears to be drawn into the orifice from upstream and downstream of the orifice. At the peak suction phase of the actuator cycle and as might be expected, the actuator appears to draw fluid disproportionately from the upstream flow. The effect of the forming vortex ring is to block the boundary layer flow in the vicinity of the orifice. An attached boundary layer still appears to exist downstream of the orifice, and between this boundary layer and the separated boundary layer from upstream of the orifice, there exists a weak wake-like region. In examining the sequence of flow fields, it appears that the vortex ring does not escape the vicinity of the orifice with the result that vortex rings are alternately formed and re-ingested at the orifice.

At the higher value of the stroke $\left(\mathrm{L}_{\circ} / \mathrm{D}_{\circ}=2.0\right)$, the flow pattern is decidedly different (figure 5$)$. The forming vortex ring (figure $5 \mathrm{a}-\mathrm{c}$ ) appears to block the boundary layer flow entirely causing it to divert around and also to be entrained into the forming ring. The vortex ring does not appear to be forming symmetrically with respect to the axis of the orifice, and vorticity from the boundary layer downstream of the orifice partially obscures the downstream portion of the ring. By the end of the expulsion portion of the actuator cycle (figure $5 \mathrm{~d}$ ), the forming vortex ring has penetrated to a height of $1.2 \mathrm{D}$ 。 above the orifice. The initiation of the suction portion of the cycle detaches the ring from the orifice. At $\phi=216^{\circ}$, the induced motion at the wall from the vortex ring appears to have created a small region, about one orifice diameter in extent, of separated flow. It is interesting to note that during suction, fluid appears to be drawn primarily from the upstream boundary layer. Clearly, without the vortex ring shielding the orifice from the upstream boundary layer, the actuator draws less fluid from the downstream side of the orifice. As the next actuator cycle begins, the vortex ring penetrates deep into the cross-flow, reaching a height of three orifice diameters. An upstream tilting of the vortex ring, typical of such flows, is also visible as the ring penetrates the cross-flow.

Profiles of the vertical component of the velocity across the orifice exit $\left(y / D_{\circ} \approx 0\right)$ were extracted from the phase-averaged measurements (figure 6). During the expulsion portion of the cycle at $\mathrm{L}_{\circ} / \mathrm{D}_{\circ}=1.0$ (figure 6a, open symbols), the profile is initially symmetric with the velocity peaking around the edge of the orifice. As the cycle progresses, the profile initially becomes more uniform before developing an asymmetry in the form of a peak at the downstream edge. Comparing the profile at $\phi=126^{\circ}$ to the flow-field snapshot at the same phase angle (figure 4c), we see that the incoming boundary layer decelerates the flow from the upstream section of the orifice while the flow from the downstream section exits unimpeded. During the suction portion of the cycle (closed symbols), peaks in the profile are again apparent around the perimeter of the orifice. The profiles then become approximately uniform before developing a pronounced peak at the upstream edge. Here it is the downstream edge of the vortex ring that initially blocks the flow into the orifice (figure 4e). As the ring is re-ingested, the blockage effect diminishes, and the flow into the orifice becomes more uniform.

With the longer stroke $\mathrm{L}_{\circ} / \mathrm{D}_{\circ}=2.0$ (figure $6 \mathrm{~b}$ ), the symmetry in the profile at the beginning of the actuator cycle has been replaced by a strong asymmetry with a peak velocity at the upstream edge nearly twice as large as on the downstream edge. From figure 5(a), the orientation of the velocity vectors above the upstream edge of the orifice suggests that, initially, the cross-flow deflects the fluid from the orifice vertically, locally accelerating it. As the cycle progresses, the profiles become more uniform, resembling a top-hat profile with boundary layer effects at the edges by $\phi=126^{\circ}$. During the suction portion of the cycle, the asymmetry is again initially more pronounced at the upstream edge with the profile then becoming more uniform. The upstream peak in the profile during the suction portion of the cycle reflects the preferential drawing of fluid from the upstream flow. Figure 5(d) shows that the induced motion of the vortex ring prevents fluid from being drawn from downstream of the orifice. 


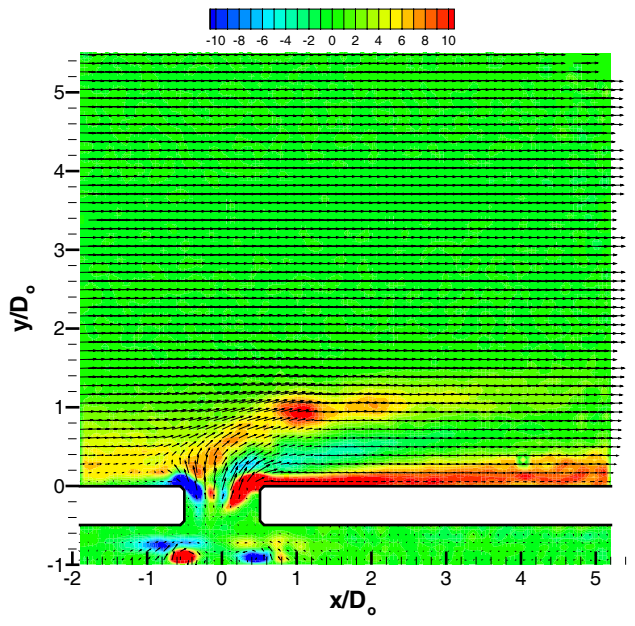

(a) $\phi=54^{\circ}$

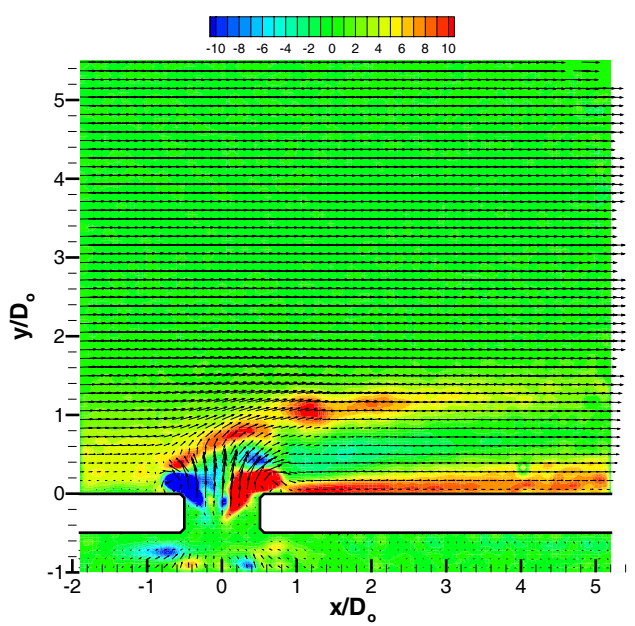

(c) $\phi=126^{\circ}$

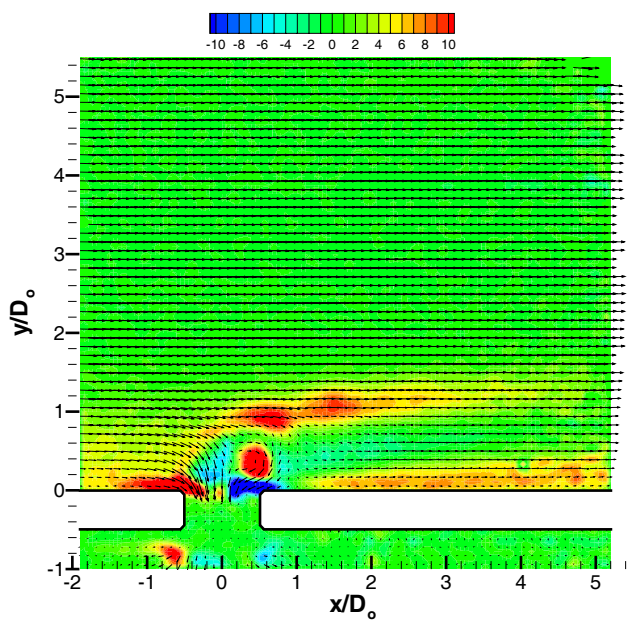

(e) $\phi=270^{\circ}$

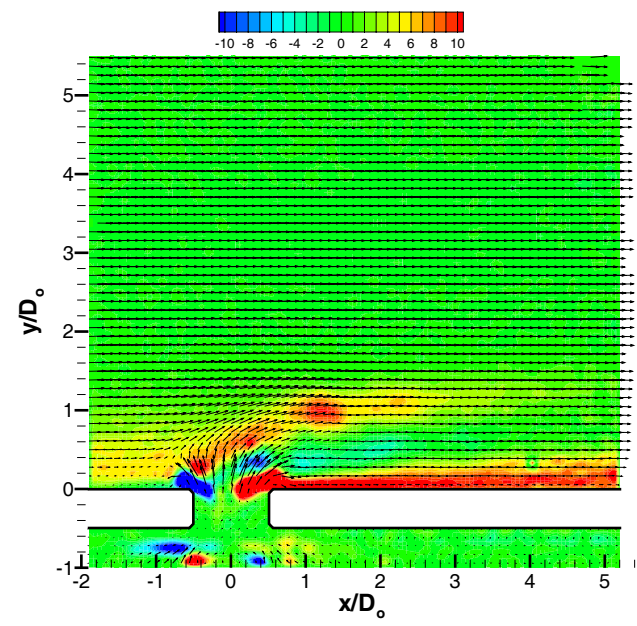

(b) $\phi=90^{\circ}$

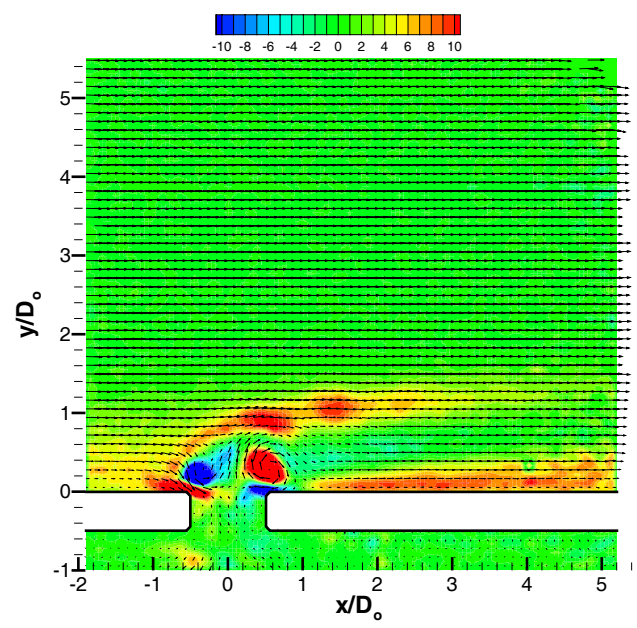

(d) $\phi=216^{\circ}$

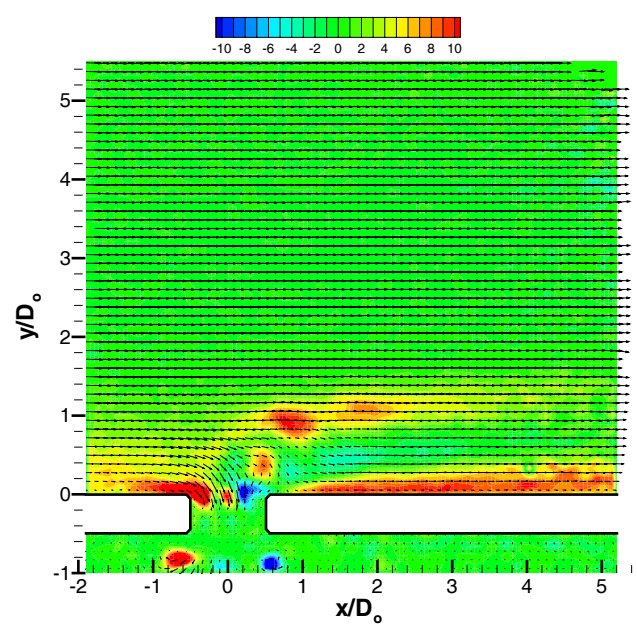

(f) $\phi=324^{\circ}$

Figure 4. Contours of spanwise vorticity, $\omega_{z}$, on the centerplane with an overlay of velocity vectors for the phase-averaged measurements of the straight orifice, $\mathbf{L}_{\circ} / \mathbf{D}_{\circ}=\mathbf{1 . 0}, R_{U_{\circ}}=250, r=1.12$.

$$
6 \text { of } 16
$$




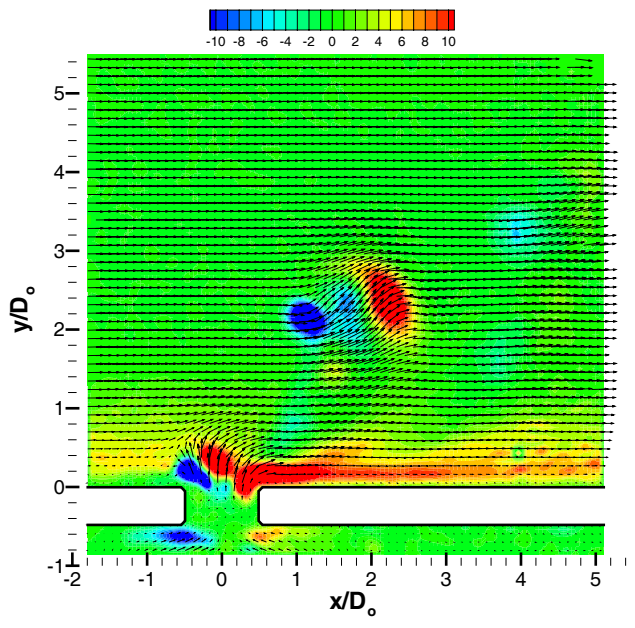

(a) $\phi=54^{\circ}$

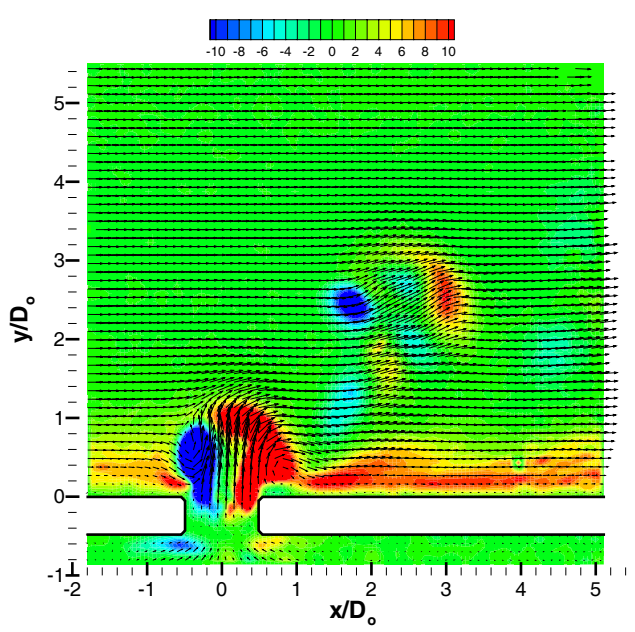

(c) $\phi=126^{\circ}$

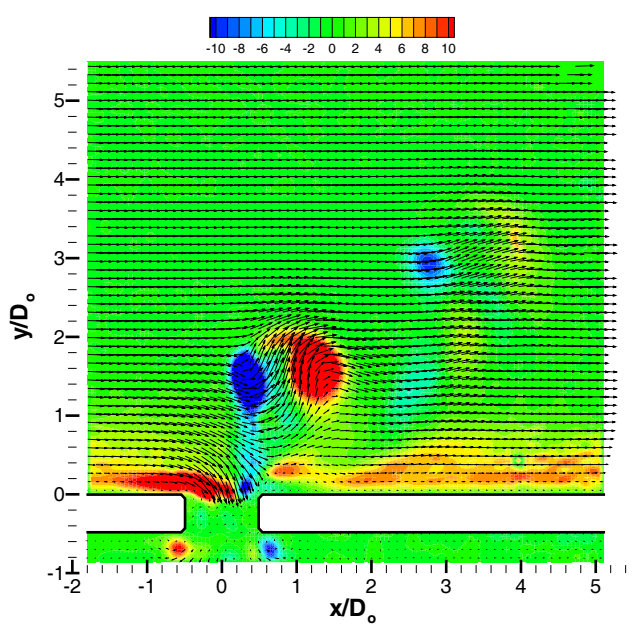

(e) $\phi=270^{\circ}$

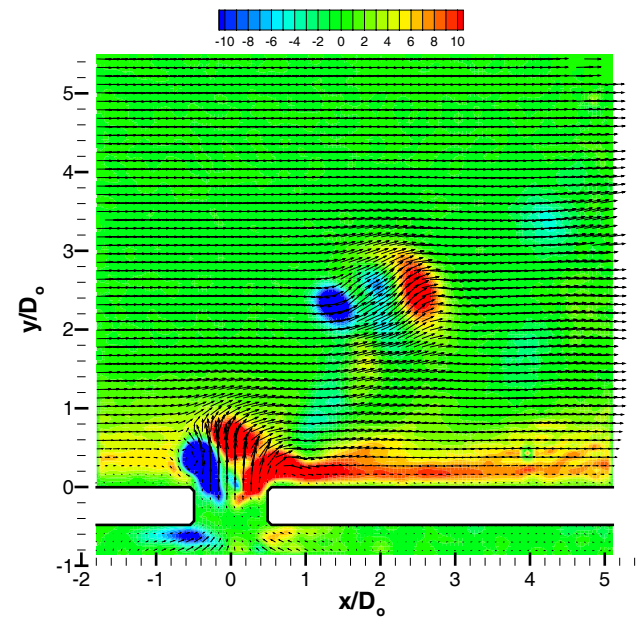

(b) $\phi=90^{\circ}$

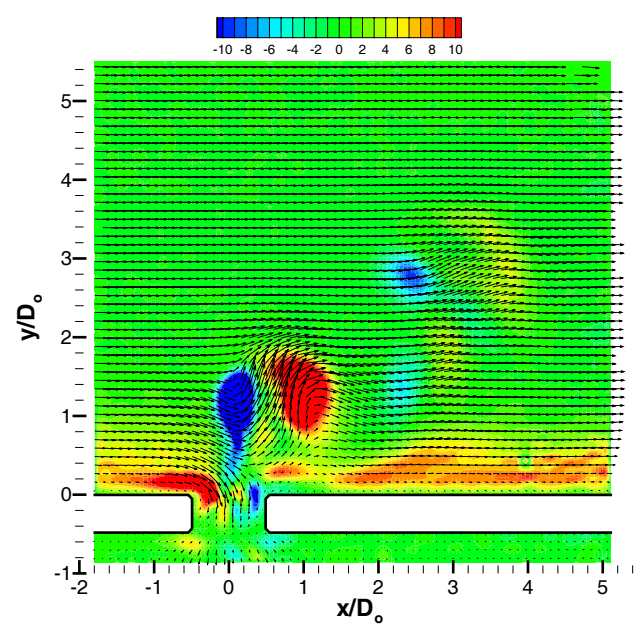

(d) $\phi=216^{\circ}$

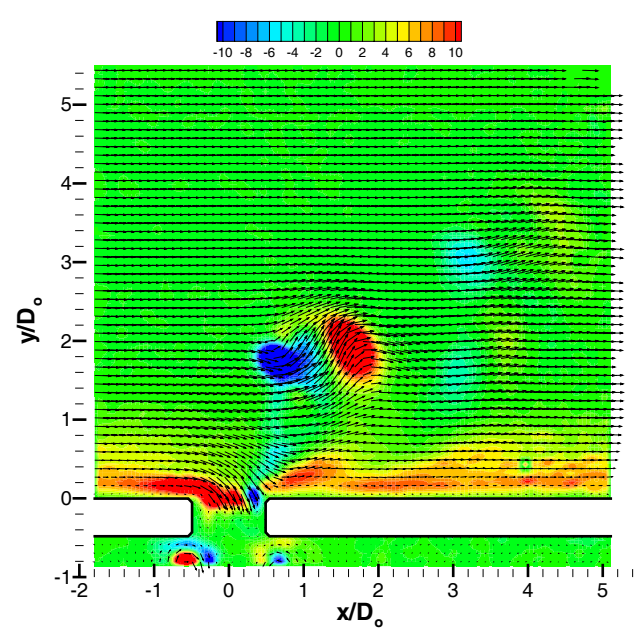

(f) $\phi=324^{\circ}$

Figure 5. Contours of spanwise vorticity, $\omega_{z}$, with an overlay of velocity vectors for the phase-averaged measurements of the straight orifice, $\mathbf{L}_{\circ} / \mathbf{D}_{\circ}=1.0, R_{U_{\circ}}=250, r=1.12$.

$$
7 \text { of } 16
$$




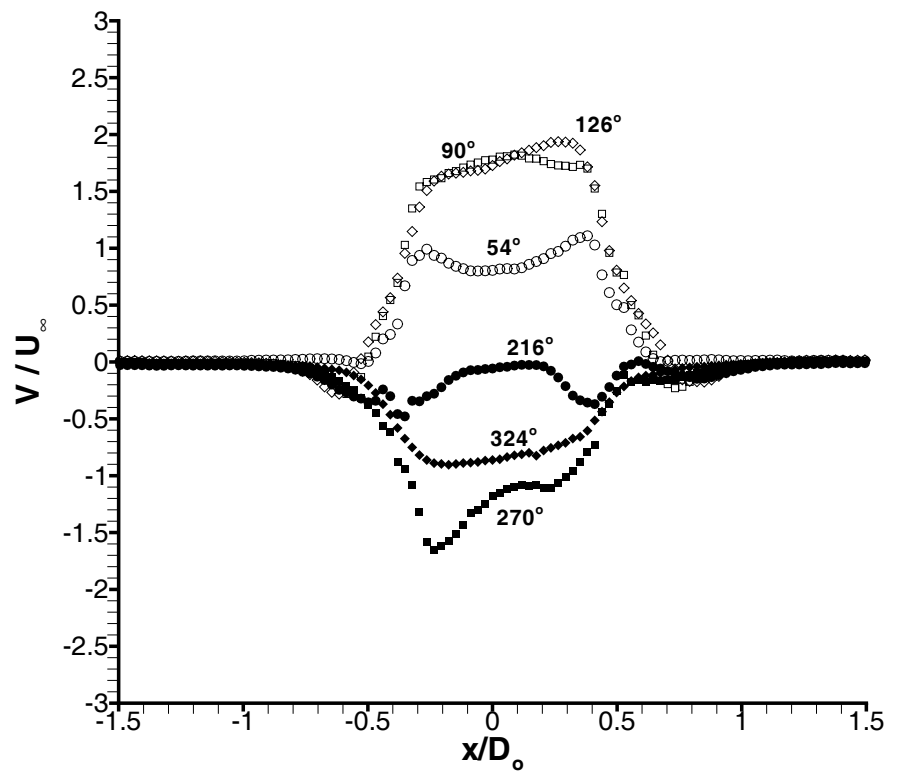

(a) $\mathrm{L}_{\circ} / \mathrm{D}_{\circ}=1.0$

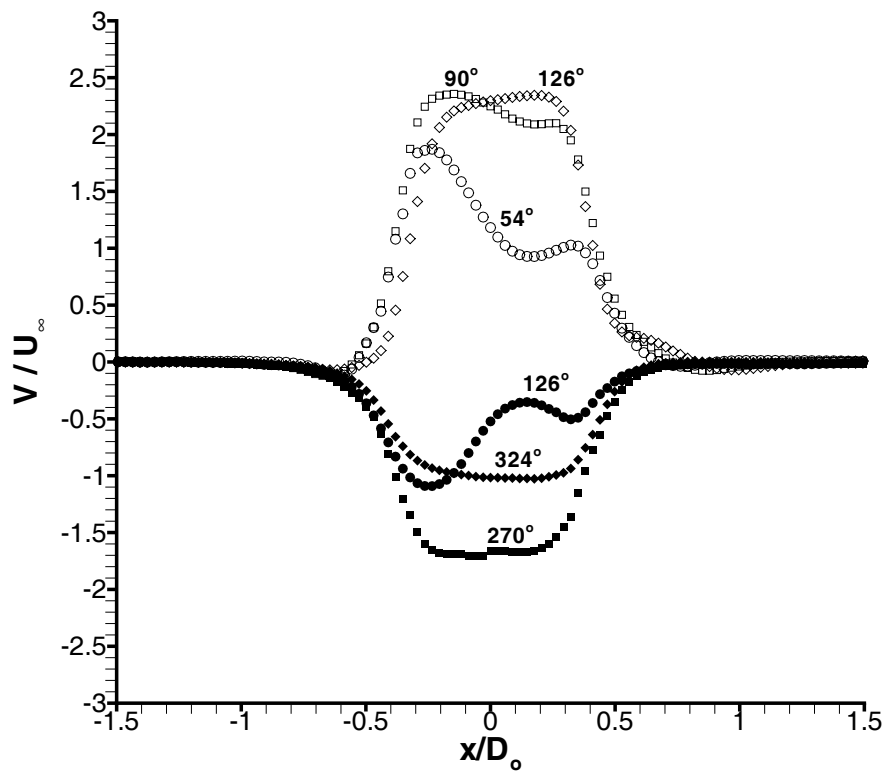

(b) $\mathrm{L}_{\circ} / \mathrm{D}_{\circ}=2.0$

Figure 6. Phase-averaged profiles of the vertical velocity, $\mathrm{V}$, at $\mathrm{y} / \mathrm{D}_{\circ} \approx 0$ for the straight orifice.

$$
8 \text { of } 16
$$




\section{B. Synthetic Jet from a Straight Orifice in a Cross-Flow: Mean Flow}

The integrated effect of the time dependent behavior on the mean flow is shown in figure 7 at both values of $\mathrm{L}_{\circ} / \mathrm{D}_{\circ}$. Here, we show, superposed, color contours of the mean streamwise component of the velocity and line contours of the stream function, $\psi$, obtained by integrating over the mean flow field. At $\mathrm{L}_{\circ} / \mathrm{D}_{\circ}=1.0$, the local blocking of the boundary layer at the actuator orifice is readily apparent with one region of reduced velocity located just above the upstream edge of the orifice, and a second region extending to approximately $4 \mathrm{D}_{\circ}$ downstream. Beyond $\mathrm{x} / \mathrm{D}_{\circ}=4.0$, it appears that the boundary layer is thinner than the upstream boundary layer, a consequence perhaps of the reorientation of boundary layer vorticity in the flow outside of the measurement plane. In the mean, the flow at the orifice also pushes the boundary layer edge away from the wall by approximately $0.4 \mathrm{D}_{\circ}$. Above the boundary layer, there is a region of the freestream that appears to have accelerated as the flow passes over the boundary layer actuator interaction. The stream function contours, indicating mean streamlines, support the apparent fuller and thinner boundary layer downstream of the interaction. Two closed streamlines at the downstream edge of the orifice suggest a small recirculation region arising from the formation and re-ingestion of a vortex ring during each actuator cycle.

At $\mathrm{L}_{\circ} / \mathrm{D}_{\circ}=2.0$ (figure $7 \mathrm{~b}$ ), the influence of the actuator is more localized in the streamwise direction. At this stroke, it is clear that, on average, the flow penetrates much deeper into the cross-flow and well beyond the edge of the boundary layer. In the mean, the actuator appears to move boundary layer fluid away from the wall, accelerating it. The net effect is that the flow above $y / D_{\circ}=3$ is undeflected by the interaction between the jet and the boundary layer. The extent of the interaction between the actuator and the cross-flow appears to be confined to no more than $3 \mathrm{D}$ 。 downstream. Here again, farther downstream, the boundary layer appears to be thinner than upstream.

\section{Synthetic Jet from a $30^{\circ}$ Inclined Orifice in a Cross-flow: Phase-averaged Flow}

For the same actuator operating conditions as the straight orifice $\left(\mathrm{L}_{\circ} / \mathrm{D}_{\circ}=1.0, \mathrm{Re}_{U_{\circ}}=250\right)$ inclining the axis of the orifice downstream at $30^{\circ}$ to the vertical leads to a dramatic change in the flow. Contours of the spanwise vorticity, $\omega_{z}$, with an overlay of velocity vectors are presented in figure 8 at six phase angles for the inclined orifice. During the expulsion portion of the actuator cycle (figure 8a-c), the flow separating from the downstream inside edge of the orifice causes the vortex ring to form with a smaller diameter in the upstream half of the orifice. At the beginning of the suction portion of the cycle $\left(\phi=216^{\circ}\right)$, fluid is drawn into the orifice from a narrow region between the wall and the nascent vortex ring. The induced motion of this vortex ring in the surrounding fluid diverts fluid up and away from the downstream edge of the orifice. Boundary layer fluid (shown with positive vorticity) that separates from the upstream, outside edge of the orifice and is present in the orifice at the beginning of the expulsion portion of the actuator cycle is expelled from the orifice and is wrapped into the formation vortex ring. Later in the cycle the vortex ring appears to "entrain" fluid and vorticity from the boundary layer located near the downstream edge of the orifice, creating a small region of separated flow (figure 8e). In this configuration, the jet appears as a train of vortex rings with as many as four rings, or portions of the rings, visible in the field of view. It is interesting to note that while the vortex ring is forming at the orifice, it begins to rotate counter-clockwise with the rotation continuing throughout the actuator cycle. As the next actuator cycle begins, the vortex ring is convected downstream without additional rotation, and appears to follow a trajectory that is parallel to the plane in which the vortex ring lies. As the rings are convected downstream, the upstream portion of the vortex ring becomes diffuse and is no longer apparent beyond $\mathrm{x} / \mathrm{D}_{\circ}=3.0$. In contrast, the downstream portion of the ring, perhaps as a consequence of additional, entrained vorticity from the boundary layer, is still evident at $\mathrm{x} / \mathrm{D}_{\circ}=5.0$. It is unclear to what extent successive rings are interacting, and whether or not, it is an interaction between rings that leads to the disappearance of the upstream portion of the rings.

The flow fields for $\mathrm{L}_{\circ} / \mathrm{D}_{\circ}=2.0$ are shown in figure 9. Here during the expulsion portion of the actuator cycle, the forming vortex ring appears to block the incoming boundary layer flow causing a deceleration

of the boundary layer upstream of the orifice and diverting the boundary layer fluid into the vortex ring. Downstream of the orifice, though, there appears to be an acceleration of the flow near the wall (figure $9 \mathrm{~b}$ ).

9 of 16

American Institute of Aeronautics and Astronautics Paper 2005-4749 


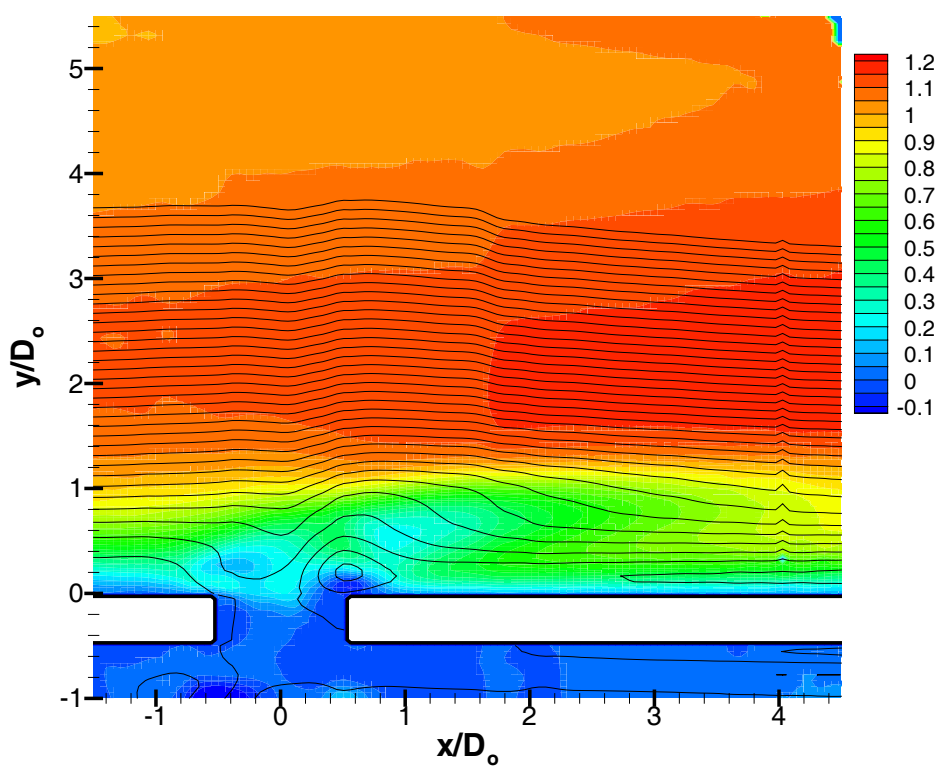

(a) $\mathrm{L}_{\circ} / \mathrm{D}_{\circ}=1.0$

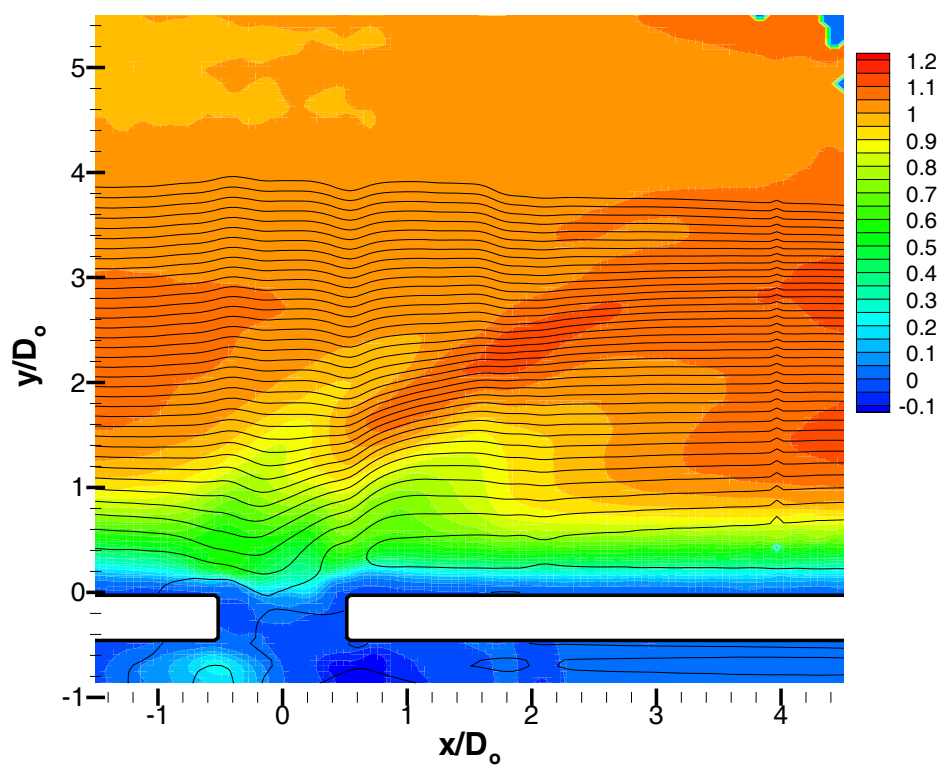

(b) $\mathrm{L}_{\circ} / \mathrm{D}_{\circ}=2.0$

Figure 7. Contours of the mean streamwise velocity (color) and the stream function, $\psi$, (lines) for the straight orifice at $\mathbf{R e}_{U_{\circ}}=250$. 


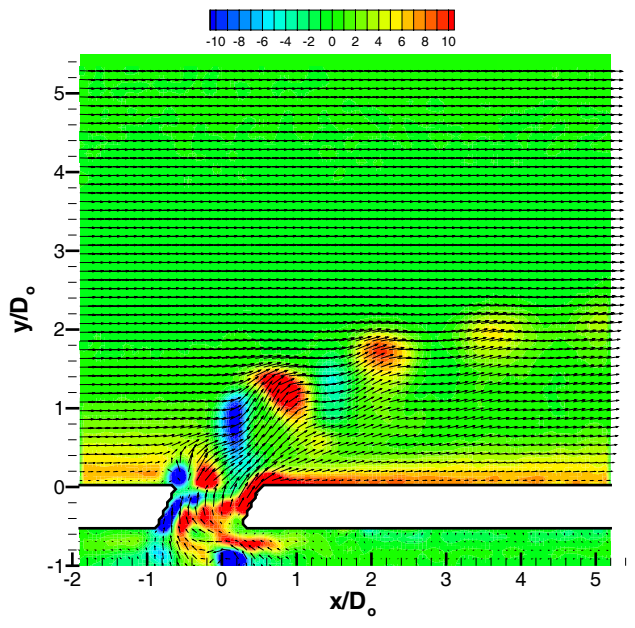

(a) $\phi=54^{\circ}$

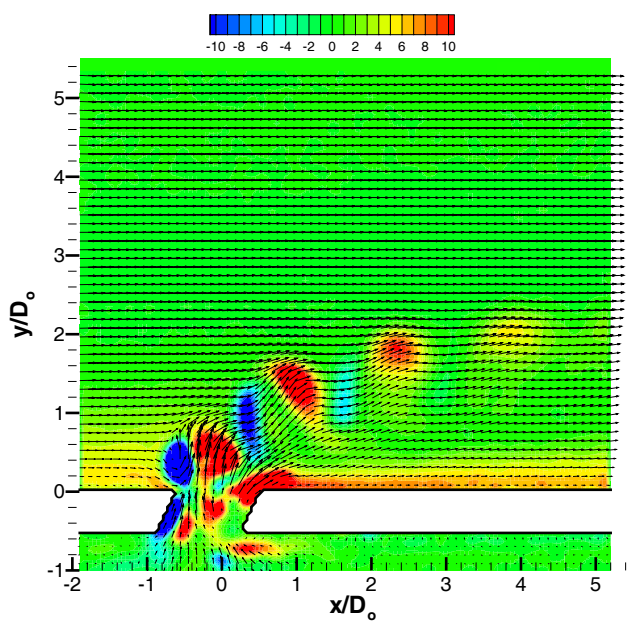

(c) $\phi=126^{\circ}$

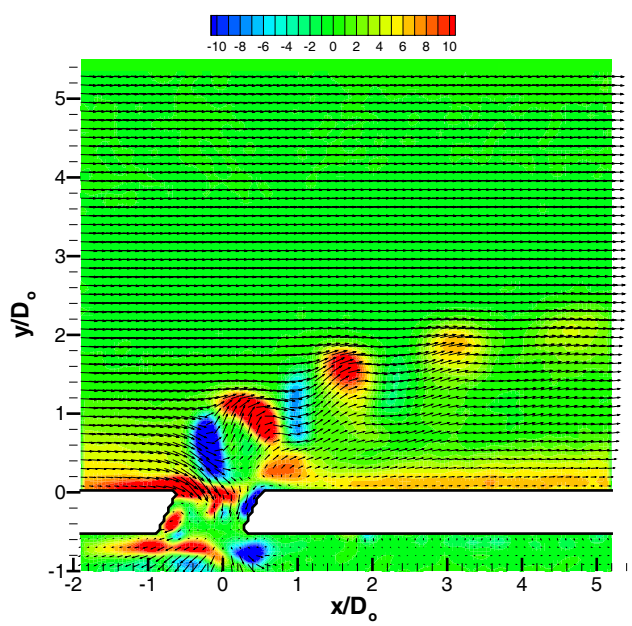

(e) $\phi=288^{\circ}$

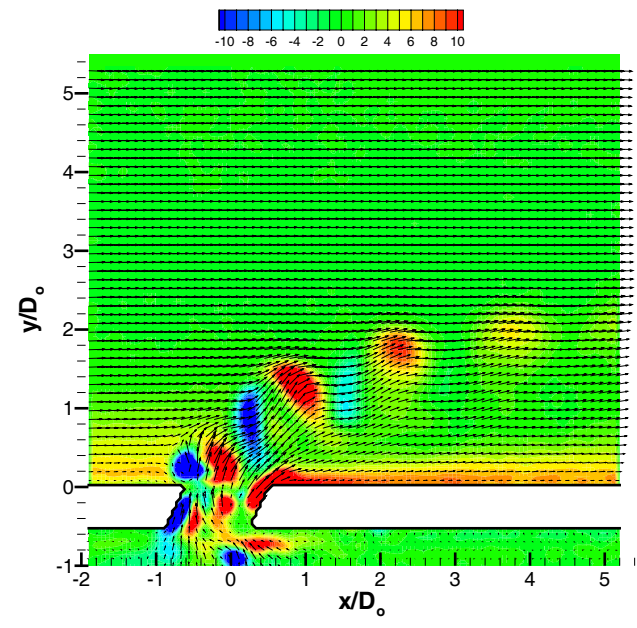

(b) $\phi=90^{\circ}$

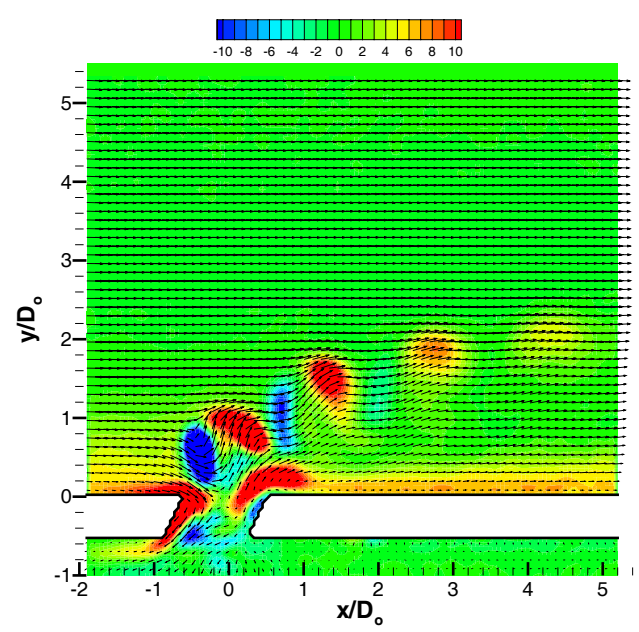

(d) $\phi=216^{\circ}$

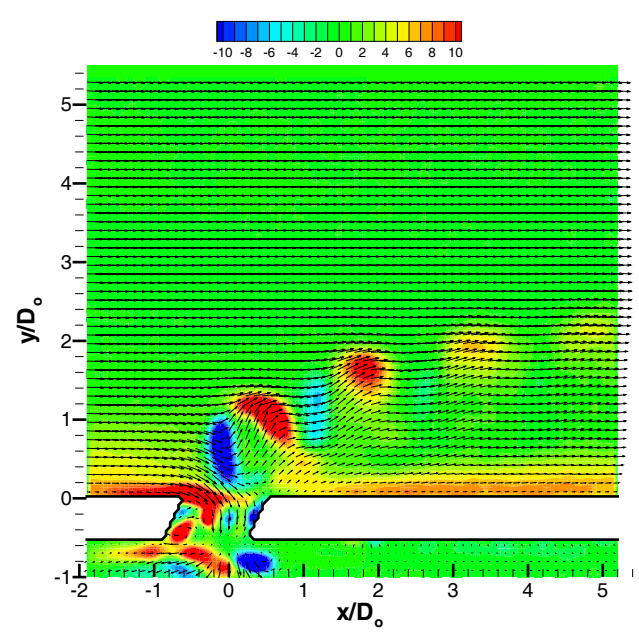

(f) $\phi=324^{\circ}$

Figure 8. Contours of spanwise vorticity, $\omega_{z}$, with an overlay of velocity vectors for the phase-averaged measurements of the inclined orifice, $\mathbf{L}_{\circ} / \mathbf{D}_{\circ}=\mathbf{1 . 0}, \mathbf{R e}_{U_{\circ}}=\mathbf{2 5 0}, r=1.12$. 
As the actuator cycle progresses, the downstream portion of the forming vortex ring entrains fluid from the boundary layer downstream of the orifice, and creates a region of separated flow, extending more than one orifice diameter immediately downstream of the orifice. As the vortex ring is carried into the cross-flow and away from the orifice, a region of fluid, identifiable by significant vertical velocity component, follows the vortex ring drawing low momentum fluid away from the wall as it moves. During the suction portion of the actuator cycle, fluid is drawn preferentially from the boundary layer upstream of the orifice. Increasing the stroke while maintaining the same Reynolds number increases the size of the vortex rings and leads to a deeper penetration of the rings into the cross-flow.

Profiles of the vertical component of the velocity across the orifice exit $\left(y / D_{\circ} \approx 0\right)$ were extracted from the phase-averaged measurements and are shown in figure 10. During expulsion at $\mathrm{L}_{\circ} / \mathrm{D}_{\circ}=1.0$ (figure 10a, open symbols), the profile initially has two peaks with the larger of the two near the downstream edge of the orifice. These peaks diminish, and the profile becomes more uniform by $\phi=90^{\circ}$, before again developing a peak near the downstream edge of the orifice. Comparing these expulsion profiles to the velocity vector fields in figures 8(a) - (c), we see that the forming vortex ring, as it interacts with the incoming boundary layer, blocks the upstream edge of the orifice. As the forming ring moves away from the orifice, this blockage diminishes and fluid exits the orifice more uniformly. During suction (closed symbols), the profile peaks on the upstream side of the orifice, and as the cycle progresses, the peak increases as it moves towards the center of the orifice. Here again, the non-uniformity in the profile is a result of the nascent vortex ring above the orifice (figure 8d). Early in the suction portion of the cycle, the ring restricts fluid motion into the orifice from downstream, but as the vortex moves away from the orifice the effect is reduced and the profile becomes more uniform.

At $\mathrm{L}_{\circ} / \mathrm{D}_{\circ}=2.0$ during expulsion (figure 10b, open symbols), a peak initially develops near the upstream edge, as the flow from the orifice is deflected vertically (figure 9a). As the expulsion continues, the peak moves downstream making the profile initially appear more uniform. As the expulsion concludes, the upstream portion of the forming vortex ring partially blocks the orifice, and the velocity profile develops an apparent peak near the downstream edge of the orifice. During suction (closed symbols), a peak in the profile initially near the upstream edge of the orifice moves towards the center of the orifice as the cycle progresses.

\section{Synthetic Jet from a $30^{\circ}$ Inclined Orifice in a Cross-flow: Mean Flow}

By inclining the orifice downstream, the wall normal and streamwise extents of the boundary layer affected by the actuator flow when $\mathrm{L}_{\circ} / \mathrm{D}_{\circ}=1.0$ (figure 11a) are increased significantly by comparison to the straight orifice (figure $7 \mathrm{a}$ ). The interaction extends to nearly $2 \mathrm{D}$ 。 above the wall, and in the streamwise direction, the interaction reaches beyond $5 \mathrm{D}_{\circ}$. The local acceleration of the freestream observed for the straight orifice is also seen here, but starts farther downstream. The mean streamlines reveal a clear deflection of the flow away from the wall for $y / D_{\circ}<2.0$ with the consequence that there is a rapid thickening of the boundary layer at the orifice.

At $\mathrm{L}_{\circ} / \mathrm{D}_{\circ}=2.0$ (figure $11 \mathrm{~b}$ ), the mean interaction is confined primarily to the boundary layer downstream of the orifice, and extends to approximately $3.5 \mathrm{D}$ 。 downstream. In the wall normal direction, the interaction reaches to $\mathrm{y}=2 D_{\circ}$. In contrast to the straight orifice, the deflection of the flow is larger in the wall normal direction and persists farther downstream. The streamlines reveal that the mean flow is drawn down toward the orifice then accelerated up and away from the wall with no net apparent change in the mean streamlines far $\left(y / D_{\circ}>2.0\right)$ from the wall.

\section{Conclusions}

The interaction of a circular synthetic jet with a laminar cross-flow boundary layer was examined. Two orifice orientations were examined, straight and inclined, at two values of $\mathrm{L}_{\circ} / \mathrm{D}_{\circ}$. At $\mathrm{L}_{\circ} / \mathrm{D}_{\circ}=1.0$, the contrast between the straight orifice and the inclined orifice is dramatic. For the straight orifice, the vortex ring that forms at the orifice during the expulsion portion of the actuator cycle does not escape the near-

12 of 16

American Institute of Aeronautics and Astronautics Paper 2005-4749 


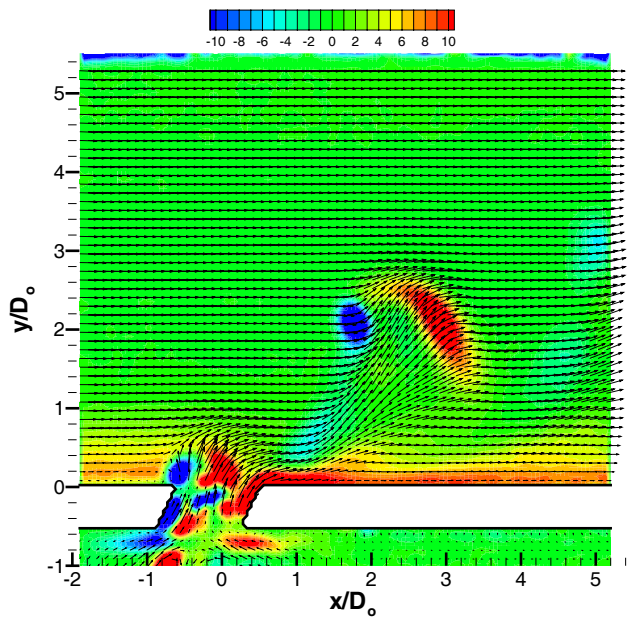

(a) $\phi=54^{\circ}$

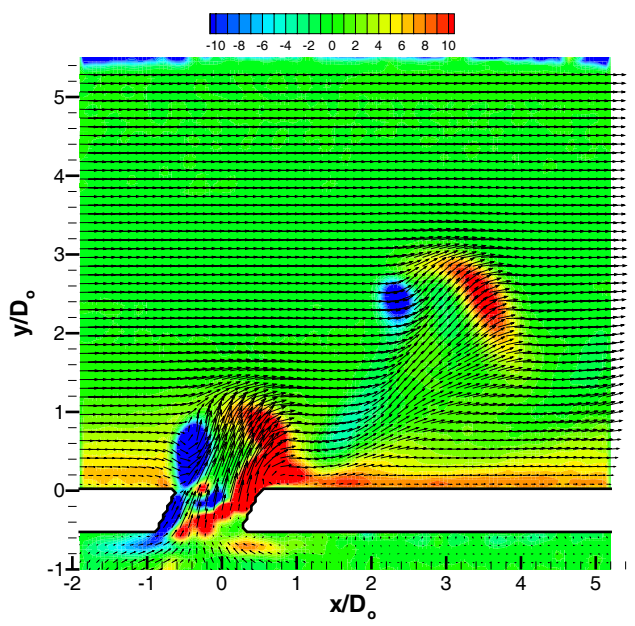

(c) $\phi=126^{\circ}$

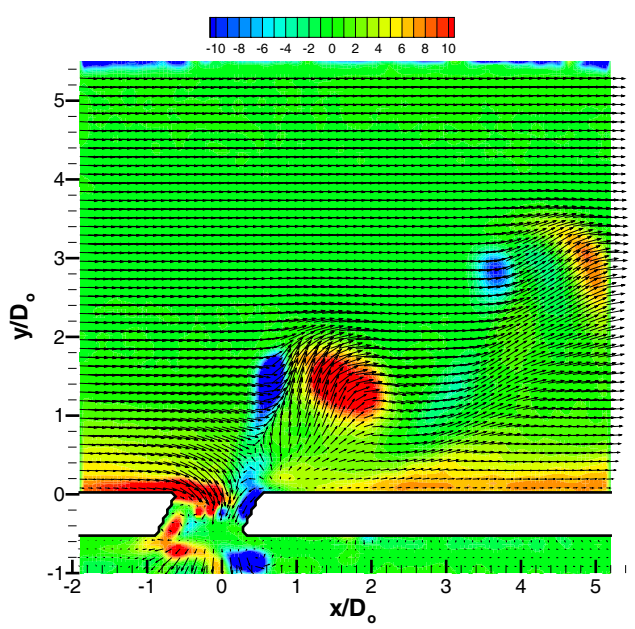

(e) $\phi=270^{\circ}$

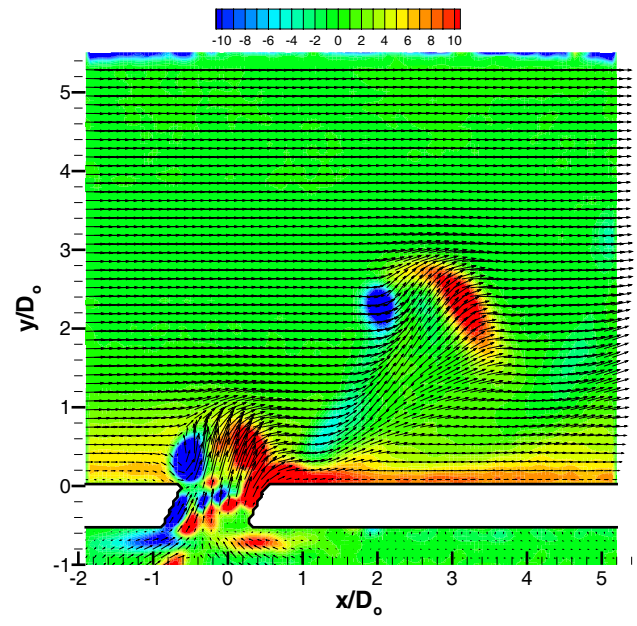

(b) $\phi=90^{\circ}$

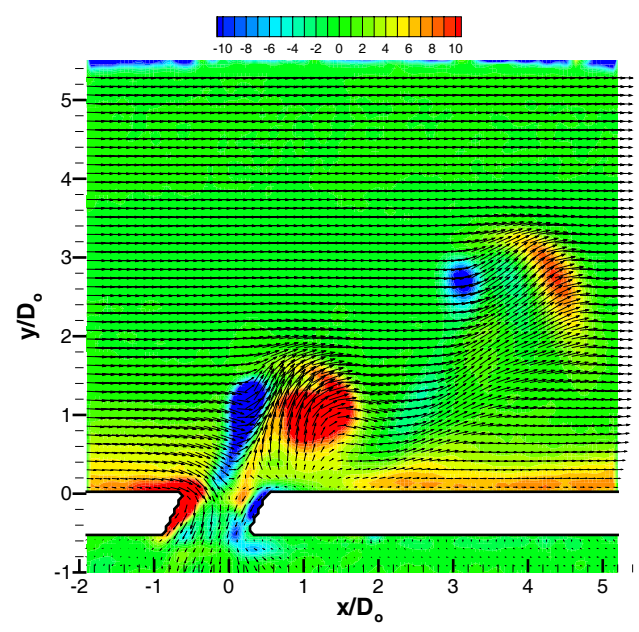

(d) $\phi=216^{\circ}$

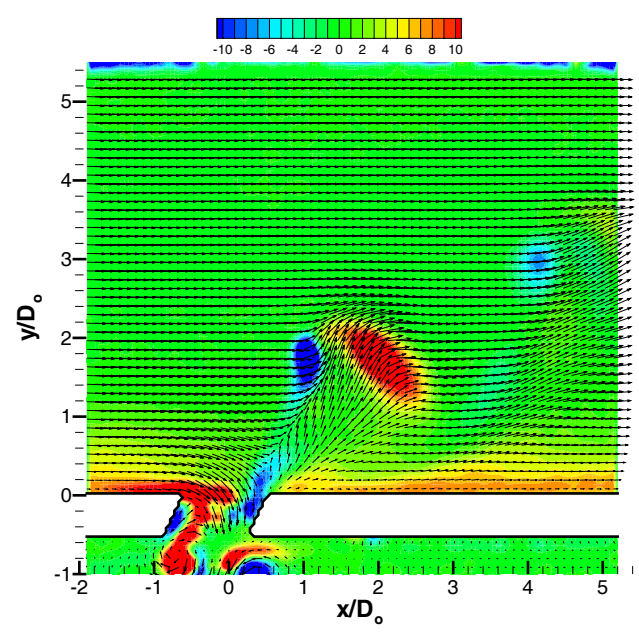

(f) $\phi=324^{\circ}$

Figure 9. Contours of spanwise vorticity, $\omega_{z}$, with an overlay of velocity vectors for the phase-averaged measurements of the inclined orifice, $\mathbf{L}_{\circ} / \mathbf{D}_{\circ}=\mathbf{2 . 0}, \mathbf{R e}_{U_{\circ}}=\mathbf{2 5 0}, r=1.12$. 


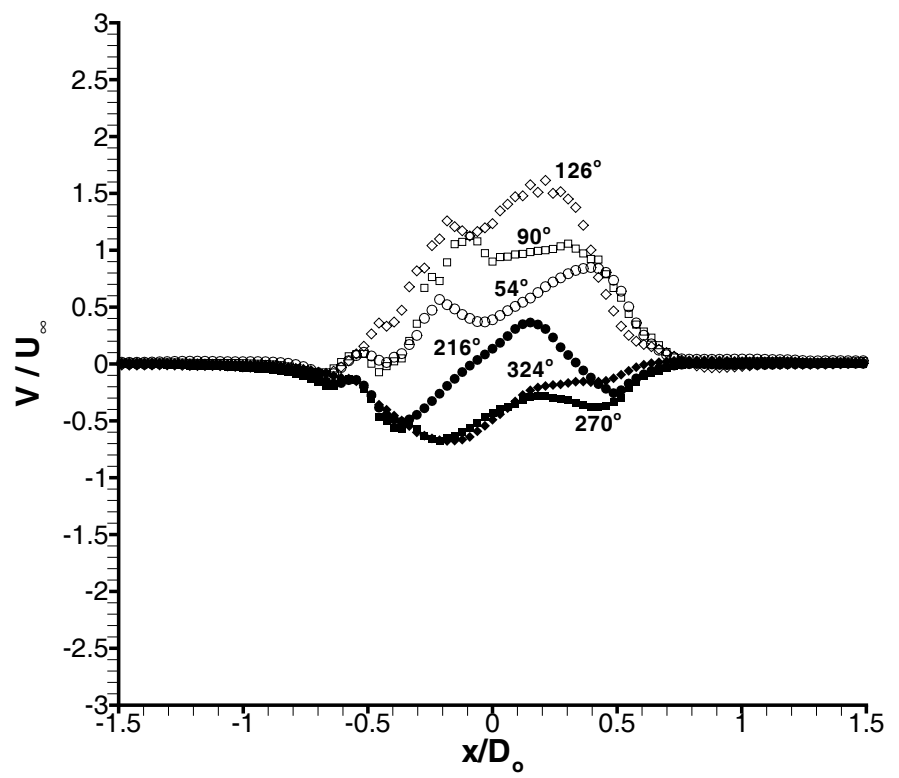

(a) $\mathrm{L}_{\circ} / \mathrm{D}_{\circ}=1.0$

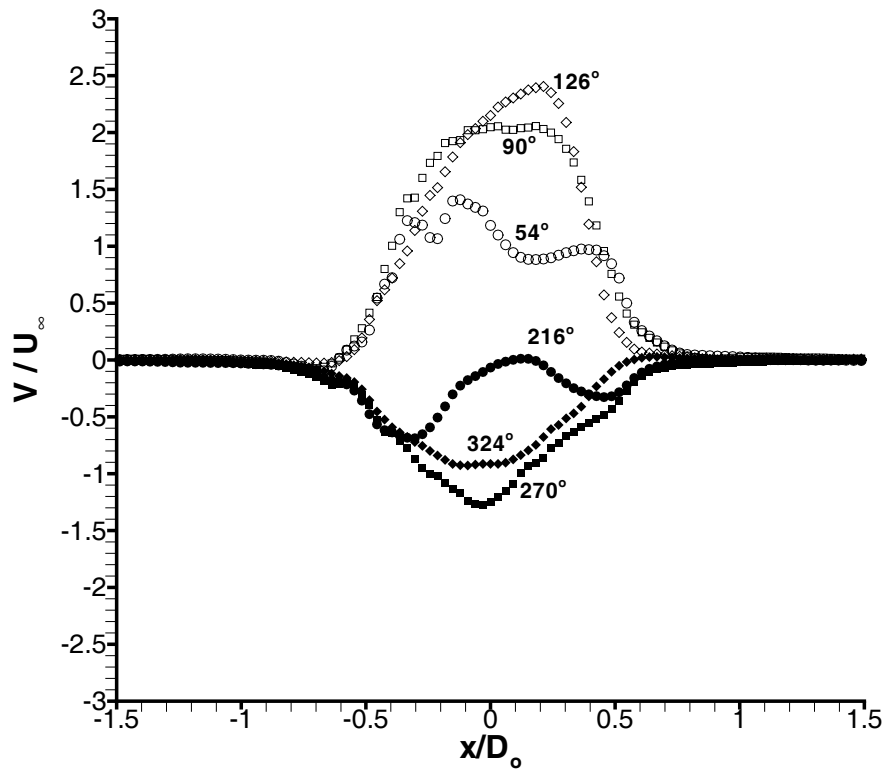

(b) $\mathrm{L}_{\circ} / \mathrm{D}_{\circ}=2.0$

Figure 10. Phase-averaged profiles of the vertical velocity at $y / D_{\circ} \approx 0$ for the inclined orifice. 


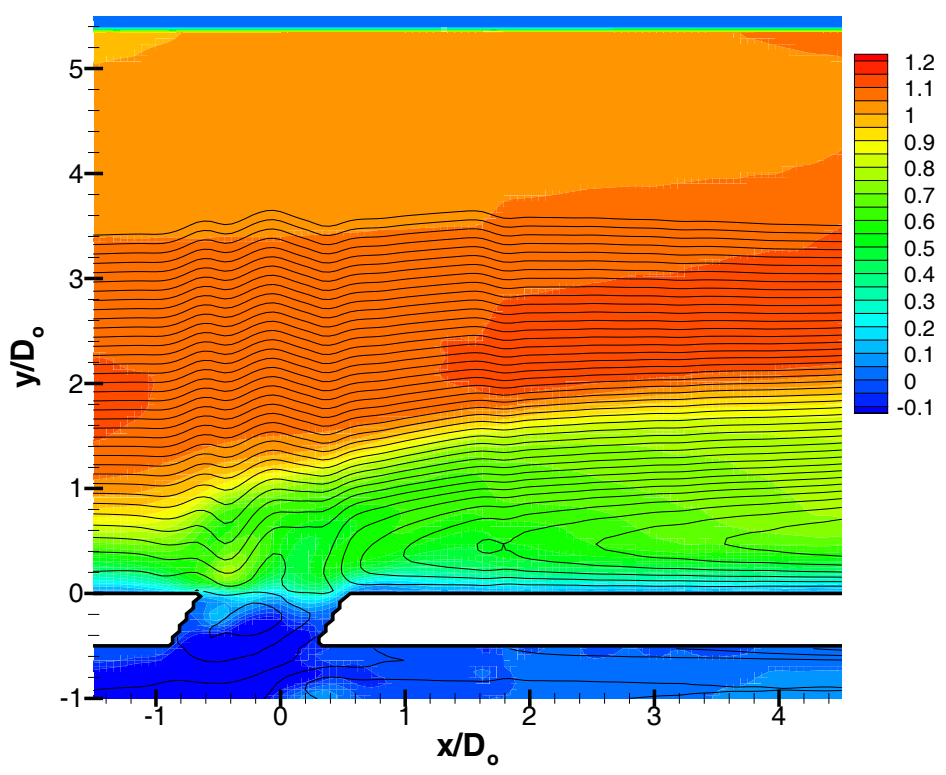

(a) $\mathrm{L}_{\circ} / \mathrm{D}_{\circ}=1.0$

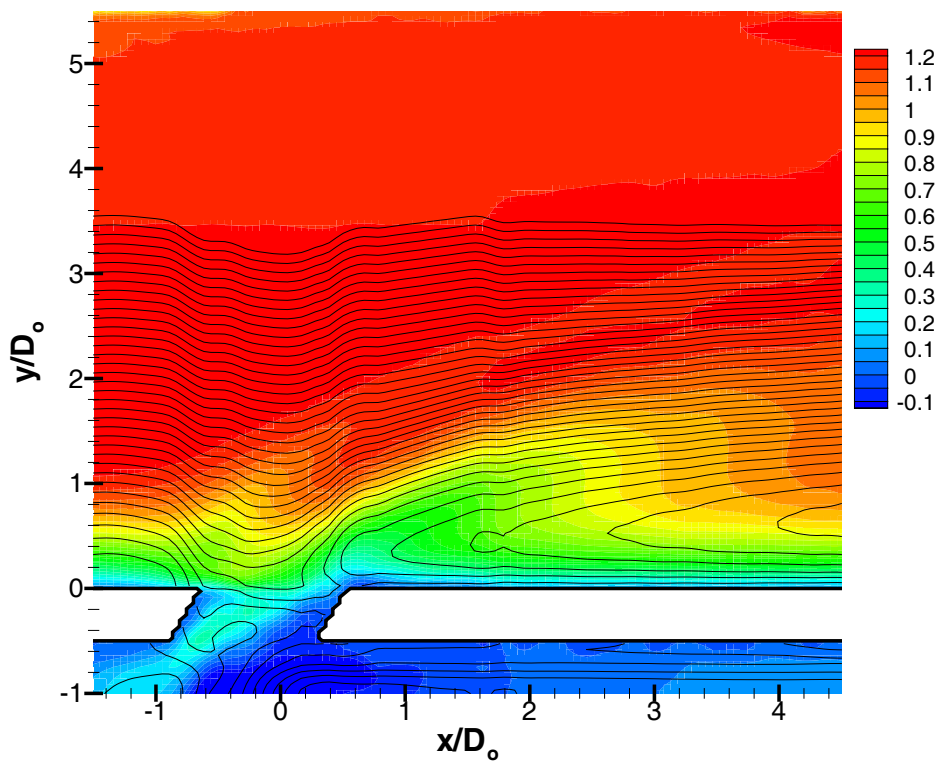

(b) $\mathrm{L}_{\circ} / \mathrm{D}_{\circ}=2.0$

Figure 11. Contours of the mean streamwise velocity (color) and the stream function, $\psi$, (lines) for the inclined orifice at $\mathbf{R e}_{U_{\circ}}=\mathbf{2 5 0}$. 
vicinity of the orifice and is reingested during the suction portion of the cycle. The incoming boundary layer diverts over and around this stationary vortex, and a wake forms in the boundary layer downstream of the orifice. For the inclined orifice at the same stroke, a train of vortex rings, originating at the orifice, penetrates the cross-flow. In the mean, there is a rapid thickening of the boundary layer at the orifice, suggesting an apparent change in the surface shape. At $\mathrm{L}_{\circ} / \mathrm{D}_{\circ}=2.0$, large discrete vortices are formed at the orifice for both orifice orientations. These vortices penetrate deep into the cross-flow, and well beyond the boundary layer edge. In the mean, the interaction arising from the straight orifice is shorter in the streamwise direction, but extends deeper into the cross-flow, with a small deflection of the mean streamlines away from the wall. The mean interaction for the inclined orifice extends farther downstream but is confined to a region closer to the wall. The mean flow is drawn down at the orifice then deflected up and away from the wall.

\section{Acknowledgments}

This work was funded by AFOSR grant, F49620-01-1-0301, monitored by Dr. Thomas J. Beutner, and was also partly supported via DoE Operations Office contract DE-AC07-99ID13727.

\section{References}

${ }^{1}$ Smith, D. R., "The interaction of a synthetic jet with a cross-flow boundary layer," AIAA Journal, Vol. 40, No. 11, 2002, pp. 2277-2288.

${ }^{2}$ Bridges, A. B. and Smith, D. R., "Influence of orifice orientation on a synthetic jet - boundary layer interaction," $A I A A$ Journal, Vol. 41, No. 12, 2003, pp. 2394-2402.

${ }^{3}$ Milanovic, I. M. and Zaman, K. B. M. Q., "Highly inclined jets in cross-flow," AIAA 2003-0183, 41 ${ }^{\text {st }}$, AIAA Aerospace Sciences Mtg., Reno, NV, 6-9 January 2003.

${ }^{4}$ Milanovic, I. M. and Zaman, K. B. M. Q., "Synthetic jets in cross-flow, Part 2 - Jets from orifices of different geometry," AIAA 2003-3715, 33 ${ }^{\text {rd }}$ AIAA Fluid Dynamics Conference, Orlando, FL, 23-26 June 2003.

${ }^{5}$ Schaeffler, N. W., "The interaction of a synthetic jet and a turbulent boundary layer," AIAA 2003-0643, 41 ${ }^{\text {st }}$ AIAA Aerospace Sciences Mtg., Reno, NV, 6-9 January 2003.

${ }^{6}$ Glezer, A., "The formation of vortex rings," Physics of Fluids, Vol. 31, No. 12, 1988, pp. 3532-3542.

16 of 16 